\title{
The Development of Japanese Mystery Novels and Their Cultural Connotation Analysis
}

\author{
Yang Yuan \\ Beihua University Foreign Languages' College, Jilin Jilin 132013
}

Keywords: Japanese mystery novels; Development; The cultural connotation

\begin{abstract}
Japanese mystery is a literary form of Japanese literature. Although she is a detective novel in Europe and America, she can stand her own. This article from the perspective of the historical development of Japan's mystery novels, the development of the simple on Japanese mystery novels, and through the analysis of the specific reasoning novelist, analysis of Japan's reasoning the cultural connotation of the novel.
\end{abstract}

\section{Introduction}

Mystery is the existence of the history of Japanese literature is unique, is enduring literary genre in Japanese literature. In $1994 \mathrm{Mr}$. Nobel prize in literature new owner big river healthy third son once pointed out "in to the knowledge popular extremely sensitive young intellectual eye in, the 'pure literature had already died'. Or may say occupies under condition which is on the verge of death." Indeed, The market condition at present, the Japanese pure literature and creative garden is so tight. Readership is more and more small, book sales plummeting, lack of literary genres, literature ideological trend and literary criticism, it difficult to find and to build great literary field led by writer. by contrast, mystery novels of the boom is not only goes for a long time did not see cool, instead more show strong momentum. At present, in Japanese each large, medium and small bookstore and the street corner book fair exhibits inference work, type many, vast if the smoke sea, makes one forget to return eyes cannot take it all in. But infers the movie or the soap opera, the TV serial which the work reorganization becomes and so on then is the common occurrence is innumerable. Although has the good and evil intermingled to pass off fake articles for the real thing unavoidably the suspicion, but work famous expert for a long time sells does not fade, the new person emerges one after another incessantly, In the pure literature work human spirit not prosperous, quantity widowed however and has revealed potential of in the decline contemporary Japan literary arena, the deductive by not has had potential of the ultra prosperity, occupied the major part literature books market enormously and powerful, these all are the facts which is obvious to all.For what reason today which declines in the Japanese pure literature, the deductive can develop so rapidly, this article will carry on the analysis from the Japan deductive developing process and the cultural connotation aspect.

\section{Japan deductive concept meaning}

Name of source the deductive in Japan, is originally fills "the spying” two character flaws, also gradually develops the independent existence actually, distinguishes with the traditional detective story. In Japan, because after Second World War, when the Japanese cancelled with the Chinese character in "has detected" the character, this has brought inconveniently certain for the printing typesetting. In addition, Showa (1925-1988) for 21 years (1946), a former detective, President of the writers Club of novelist and physiologist mumugaotailang (1897-1969), arguing that "detective story" as the "mystery". Under his vigorously initiative, "the deductive" this concept and the name then gradually acknowledged by the general writers and the reader and follows until now.

In general, mystery novels than the detective novel contains more rigorous scientific logic. 
Simple, the deductive take the thought demonstration as the objective goal, take the case solution as the subjective goal, often draws wire in the spying in the exhausted cocoon proof to demonstrate the rational logic the recreation peer charm, simultaneously promulgates hides in the dense fog the event truth. Tell from the narrow sense, therefore, constitute the main elements of reasoning is novel, with by setting suspense and using the method of logic reasoning to criminal investigation, etc., as the detective solve matters as the main content of the novel is a mystery. In a broad sense, in addition to the detective mystery novel, violence crime novels, novels, the case-solving novels, fantasy novels, thrillers, revenge stories, adventure novels, spy novels, martial arts novels, with the reasoning and larger custom romance novels, family disputes novel and magical mystery novels, and many other popular literature form also can be included within the category of mystery novels.

\section{Japan deductive developing process and cultural connotation analysis}

During the long Japanese literature perpetual flow, the age which the deductive this novel form produced is late, experiences has germinated due-out, introduces, starts the development, the stagnation vigorously is popular the developing process again which and even the human spirit ebullition, saw one climax after another.

Meiji before may talk into is the deductive development initial period, far - such as "Ancient Matter Recorded", "Bamboo in the nara period Japanese classical literature work Takes Language", "Source Language" and so on in the literature celebrated works on already partially or includes the deductive trace fully and favors. In the edo period (1603-1867) with a detective means work officially the interest of the mass audience. By "Big Post Politics Discussed" settles a lawsuit the novel for representative's tribunal, the revenge novel, the strange tale theme and so on strange novel works starts to print being published massively, in the work quite contained the deductive flavor. Therefore, we may regard as the Meiji beforehand time the Japan deductive the seed stage.

As soon as fights in the turbulent conclusion which the experience, the Britain and America detective story has welcomed the bright gold time. Compares with it in, the Meiji initial period Japan deductive still was in October to be pregnant actually. In this case, god Tian Xiaoping will have translated "Yang Yaer in 1877 the Strange tale", the opening remarks translate beginning of a matter of the foreign inference work, take this as the beginning, the deductive mature period arrival, black crag tear fragrance, woods Tian Sixuan et al. start to respond clearly lifts the reform to open wide the entrance to a country the summons, the overseas full of beauty and significance inference work will translate Japanese, will introduce for the general Japanese readers. The translation work built the foundation for the inference culture, the Japanese original deductive unceasingly has then emerged, started to have "the native place" gradually the flavor, For instance, after Sino-Japanese War of 1894-95, the pursue bright life and the happy family novel starts popularly, therefore the deductive appeared "changed" the symptom of a trend, started to melt the family novel atmosphere the human to infer in the work.Lei Xiang has said: "The Japanese nationality is since birth one easily the mood institute about nationality, greatly strengthened and is separated from the Japanese real life scene with the logic reasoning the Western world detective story work to compare, side everywhere living real life and the inference essential factor unify the practical inference work will be easier by the Japanese reader to accept." The fact really for its word in, along with the translation foreign country detective story temperature decrease, the practical inference work once started to be lucky.

However the prosperity is not long, until the Meiji last stage, the deductive presents the stationary state, this bleak condition continues to the Taisho earlier period also not to be able continuously to have a new look. After the 1923 great Kanto earthquake, Tokyo be rebuilt, dishes to be development of the economy. This kind of objective social phenomenon has brought the turning point for the reportage and the literature development, has pulled open including the deductive popular literature vigorous development curtain. The Taisho last years, two modern deductive great master Jiang Huluan step and the catch water histories in form of biographies ride the time flood tide to appear successively in the Japanese literary arena. Edo Sichuan disorderly step (1894 - 1965) 
works well constructed, inference rigorous careful, is full of romantic colour, there is no lack of again the feeling of mysterious horror. Catchwater histories in form of biographies (1902-1984) then work rich legendary color. Because the detective story then once received the authority the limit, then started to rewrite the historical theme to settle a lawsuit the romance.

To the Shiaowa mid and late part, the deductive creation domain appeared one group of promising youths, its representative personage for present age deductive Master pine this clear Zhang Hesen village honest one. After that, the deductive style characteristic finalizes slowly, by pine this clear representative Zhang Wei, "social faction" the deductive occupies the main status slowly. The deductive stabilizes in the rough twists and turns Japanese history gets down, its experience available: “The Meiji Restoration”, “a war”, "the big earthquake”, "the public opinion control" "defeats" summary - - this also is precisely the Japanese society's experience. This is not done. By well known Matsumoto Zhang Qing, for example, is time more near to us, can borrow his works have a good look at the Japanese society. Pine this clear "is not anxious constrained by the pure hypothesis, the arrangement infers the labyrinth, finally unties the truth" the same old story deductive formula, But is anxious, infers the broken riddle the process and the social phenomenon and the social question closely unifies creatively, causes oneself and other infers the writer to distinguish purely, becomes the work content to stress the founder who sends the deductive in the exposition society question and the dark side society and to represent the writer, caused the deductive the chaotic step orthodox time to transit from Jiang Huchuan to has sent the time take him as representative's society. Matsumoto Qing Zhang masterpiece is, as it were, the most embody the spirit of "social" works: in the form of reasoning, explore the social root of crime, reveal the social contradictions, to show self contradiction and anguish. By holding up social reasoning flag, will be fully detailed description in Japanese society conflict, to top group, the rule of pen and ink and criticism. In his representative works, is praises enthusiastically to the unimportant person, although bitter experience misfortune, but many and destiny resistance. Rarer is, took unavoidably the deceased person and the metamorphosis deductive, he does not have the useful rank smell of blood pornography the writing to attract the reader. When involves these plots, he all is selects to namely stops. His artistic interest has taken to bring with his work the new altitude. It is no exaggeration to say, Matsumoto masterpiece as each reasoning fans will see novel. In Japan's position, it is equal to the status of Jin Yong's novels in China.

Transits the discipline from in his Dongye jade tablet I, is Japan which the high-school pupil university students knew very well immediately infers the writer of fiction famous. His representative works "Travelled by night are In vain" display pine this clear style the acme: By two not only is the murderer also is victim's angle, was relating but behind each case long lets the human heart pain story. The story begins by a murder case, ordinary. But looked more in the future that, more will be felt faintly has a huge plot to open the big net which nobody may hide, lets the human feel the palpitation and despairs. Draws wire the exhausted cocoon along with all, understands gradually, to Xue Hui of actions more is felt constrains. However, after all perspicuities, one kind sorrowful lets my tear class warm.We can confirm that, the lead Tong Yuan is originally has guilty and the love to the Xue Hui, but the Xue Hui is more complex to the Tong Yuan tree original sentiment: She namely to the Tong Yuan tree original father the injury deeply deeply fear and the hatred which brings to her, even shifted this mood on the Tong Yuan tree original body, but also to Tong Yuan tree original kind of dreadful indifference, Of course, if carefully read, I think it's love. But their relationship has not simply "love" summed up, I think it's more of a "bond"-Japanese people seem to like the word, they put everything in "en" links become "fetters".

Still remember the back cover of the book featured language of the novel "no stupid love, no lasting only a cold and desperate trickery, last bit of warmth have been completely abandoned, thousands of readers in a mournful moved in a dismal song salvation sins of love...." such a complex and frightening story occurred in the in prosaic narrative. Perhaps because of this contradiction, was so fascinated by Japanese mystery novels. With the mystery trend of Japan abroad, may be able to gain a better understanding of the world Japan, a country rife with contradictions. 
In the Japan deductive includes very many histories, the very many Japanese human nature, very many "the fetters" .Some people once said that, "I thought this spot thinks extremely importantly, even may say is "fatal" point: The deductive is the acme true, the good and the beautiful and the acme vacation wicked clown's contradictory body, is most can represent slaughters the beauty the literature type.Regarding a advocation oriental cherry, the advocation chrysanthemum and the knife, advocates 'radiant dying is greatest and the happy home to return to' state, but also has the ratio deductive to be able to represent Japanese's literature form?" Truly, reads the deductive, perhaps understood but but but liked to look good also militaristic, Shang Li also combative, happy new and also is stubborn, the obedience also not a docile Japanese very good method.

\section{Summary}

Japan's inference culture is at the fiery condition continuously, from novel, movie, soap opera ...... All may feel the Japanese to infer cultural frantic. Reflected the historical trend, the abbreviation social phenomenon, the revelation life true meaning, smiles satirizes the fickleness of human relationships, the eulogy true, the good and the beautiful, whips the vacation wicked clown is one of throughout literature missions. In the inference culture, the deductive is one of earliest literature expression forms, from the Japanese to its chase degree, not difficult to see it to reflect the Japanese psychology, the human nature as well as the Japanese society have classical. Only historical development which has from Japan deductive itself, might smell and it correlation social condition and Japanese's disposition characteristic. Also or, was these factors has affected the deductive creation: Japan has a strict scientific spirit, meticulous and full of imagination, which in the reasoning of the high technology content creation is indispensable. Meanwhile, the mystery is a synthesis of reason and emotion, this is also conform to complex Japanese characters.

\section{References}

[1] ShuaiSongSheng. The development and features of Japan's mystery novels [J]. Journal of contemporary foreign literature, 2000.

[2] LiZhen. Japan's mystery novels two roads [J]. Journal of luo river from the vocational and technical college, 2001 (04).

[3] Ye Weiqu. Japan mystery novels and its representative writers [J]. Journal of reading, 1979.

[4] Ma Jun. The public social and post-war Japanese mystery novels [J]. Unfold BBS, 2001.

[5] Li Dechun. Matsumoto qing zhang theory - and a review of the Japanese mystery novels [J]. Journal of graduate school of Chinese academy of social sciences, 2001 (5). 